\title{
Improved Performance of 50 kN Dead Weight Force Machine using Automation as a Tool
}

\author{
Harish Kumar ${ }^{1}$, Anil Kumar, Poonam Yadav \\ ${ }^{1}$ National Physical Laboratory (Council of Scientific \& Industrial Research), New Delhi, 110012, India, \\ E-mail: kumarh@mail.nplindia.org
}

Continuously growing technologies and increasing quality requirements have exerted thrust to the metrological institutes to maintain a high level of calibration and measurement capabilities. Force, being very vital in various engineering and non engineering applications, is measured by force transducers. Deviations in the values observed and mentioned in the calibration certificate for force transducers may primarily be due to the creep, time loading effect and temperature effect if not properly compensated. Beside these factors, machine interaction, parasitic components etc. pertaining to the quality of the force standard machine used for calibration also contribute to the deviations. An attempt has been made by National Physical Laboratory, India (NPLI) to automate the $50 \mathrm{kN}$ dead weight force machine to minimize the influence of factors other than the factors related to the machine itself. The calibration of force transducers is carried out as per the standard calibration procedure based on standard ISO 376-2004 using the automated $50 \mathrm{kN}$ dead weight force machine $(\mathrm{cmc} \pm \mathbf{0 . 0 0 3} \%(k=2))$ under similar conditions both in manual mode and automatic mode. The metrological characterization shows improved metrological results for the force transducers when the $50 \mathrm{kN}$ dead weight force machine is used in automatic mode as compared to the manual mode.

Keywords: Dead weight force machine, automation, force

\section{INTRODUCTION}

$F^{\circ}$ ORCE MEASUREMENT plays a very important role in various applications, necessitating its accurate and precision measurement. The applications are for example calibration of material testing machines, electronic weighing apparatus, force measurement in various machining processes (like turning / drilling / milling), rolling mills, thrust measurement of jet engines and rockets, installation of big or heavy machinery, weighing of aircrafts etc. This has led to the thrust over metrological institutes to maintain a high level of calibration facilities. The deviations in the values of force transducers may be due to creep, time loading effects, temperature effects, machine interaction effect, parasitic components etc. To minimize these factors, several efforts have been made, e.g., the automation of strain gauge load cell force calibration, development of computerized calibration system, development of automation system for operating the force standard machines etc. [1-3].

Though the National Physical Laboratory, India has the facilities for the calibration of force transducers from $1 \mathrm{kN}$ to $3 \mathrm{MN}$, about $50 \%$ of the force transducers calibrated falls into the range of $5 \mathrm{kN}-50 \mathrm{kN}$, which has made a precision force standard machine a necessity in this particular range. To cater the needs of precision and accurate measurement of force, $50 \mathrm{kN}$ dead weight force machine was developed by the More House Corporation, USA as per the instructions of the National Physical Laboratory, India. The main components of the dead weight force machine are the loading hanger, sets of dead weights and a rigid main frame supporting these components. The dead weight force machine employs 18 stainless steel dead weights of nominal force values ranging from $0.5 \mathrm{kN}$ to $5 \mathrm{kN}$ which take into account the local values of gravity and buoyancy correction for the applied axial force by the dead weight force machine.
The pneumatic system has been used for loading and unloading the weights to minimize the oscillations so that force is stabilized in the least possible time once applied or removed. The force in range of $0.5 \mathrm{kN}$ to $50 \mathrm{kN}$ may be applied by the force and up to $50 \mathrm{kN}$ forces may be applied in either mode (tension and compression) in any sequence desired, depending upon the force to be applied [4]. The maximum force applied is $50 \mathrm{kN}$ and hysteresis calculations can be done after applying forces in ascending order in the series and then descending in the same order [5]. The $50 \mathrm{kN}$ dead weight force machine is able to perform calibrations according to standards IS 4169-1988, ISO 376-2004 and ASTM E-74. The expanded uncertainty associated with the force applied is $\pm 0.003 \%$ ( $k=2$ ) (Fig. 1 ).

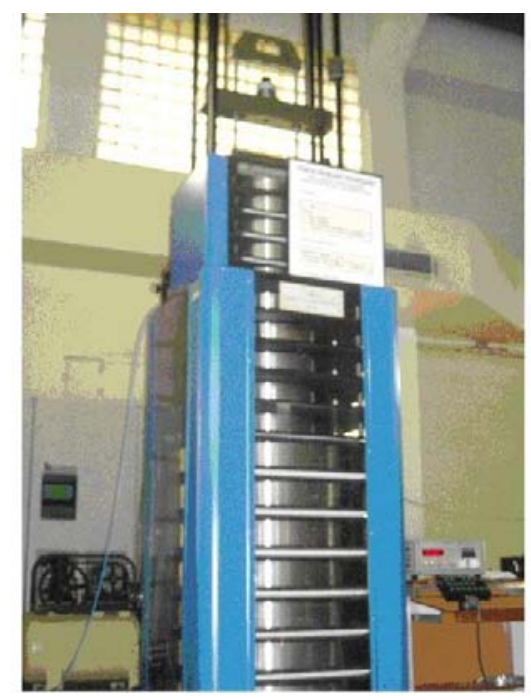

Fig.1. 50 kN Dead Weight Force Machine 
The $50 \mathrm{kN}$ dead weight force machine has been used for calibration as per the standard calibration procedure based on standard ISO 376-2004 ${ }^{6}$. The automated force machine has been used to calibrate two precision force transducers of $20 \mathrm{kN}$ and $50 \mathrm{kN}$ capacity in manual mode and automatic mode. The comparison of metrological characterization in the form of relative repeatability error and the relative reproducibility error has been presented and the effect of automation over the performance of the $50 \mathrm{kN}$ dead weight force machine has been discussed here.

\section{AutOMATION OF $50 \mathrm{KN}$ DEAD WEIGHT FORCE MACHINE}

Calibration procedure is generally monotonous and labour intensive. Any mistake during the calibration may lead to improper metrological characterization including wrong uncertainty evaluation and classification of the force transducer under calibration. Human interference also plays a vital role in the calibration process if the measurements are carried out manually. Hence, efforts have been made for a computerized calibration system [2-3]. Taking care of these views, NPLI has automated a $50 \mathrm{kN}$ dead weight force machine by customized hardware and software so that calibration can be carried out with the least possible human interference using the standard calibration procedure. The actuation of pneumatically operated solenoid valves is done through embedded server to a relay unit. The embedded server, based on micro controllers, real time operating system and semi-conductor based memory, has longer reliability. The interaction of the embedded server with the computer is through RS 232 port following the standard protocol. While interfacing, Data Bits, Baud Rate, Echo, Stop Bits, Com Port, Flow Control, Indicator Port and Digital Indicator need to be specified. The control software is a graphic user interface based user-friendly software with help facility of the user manual. Various parameters like waiting time, angle and sequence of weights need to be defined before the calibration. A high resolution digital indicator (Model DK 38, HBM Germany make) having good stability and a resolution of $5 \mathrm{ppm}$ with a data sampling rate of $50 \mathrm{~Hz}$ has been used for indicating the reading of the force transducer.

\section{OPERATION OF AUTOMATED CALIBRATION SYSTEM}

The operation of automated calibration system for force transducers consists of the following stages (Fig.2):

- Select mode - manual or automatic

- Fill necessary information about force transducer, capacity, calibrated for etc.

- Select force to be applied, sequence of force steps, waiting time at no load / full load, waiting time in between force steps

- Select the operation - preloading / get reading

- Calibrate the force transducer as per the standard procedure

- Summarizing the calibration observations

- Uncertainty evaluation

- Preparation of calibration reports and classification of force transducer

- Importing results in the form of MS Excel file
In manual mode, the operator has to apply forces after the preset time interval, while in automatic mode the computer itself controls the system and force is applied after the preset time interval and reading is stored.

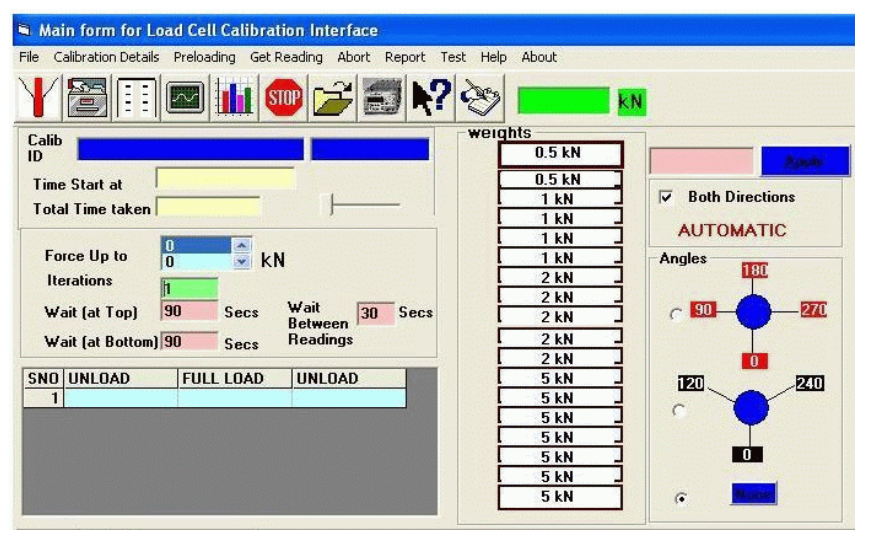

Fig.2. Menu to Control / Monitor the Observations during Calibration

\section{CALIBRATION USING MANUAL \& AUTOMATIC MODE}

Two precision force transducers of $20 \mathrm{kN}$ and $50 \mathrm{kN}$ capacity (compression type) were selected for calibration using $50 \mathrm{kN}$ dead weight force machine. The force transducers have the uncertainty of measurement $\pm 0.004 \%$ and $\pm 0.005 \%$ (at $k=2$ ), respectively. Both force transducers were calibrated as per the standard calibration procedure according to ISO 376-2004 for manual mode as well as automatic mode under controlled atmosphere, with temperature $23 \pm 1^{\circ} \mathrm{C}$ and relative humidity $50 \pm 10 \%$ [5]. The calibration was conducted for $10 \%-100 \%$ of the capacity of the force transducers with $10 \%$ incremental steps. The time interval between the readings was maintained at 30 seconds.

The calibration procedure is as follows:

- The digital indicator was switched on for 30 minutes to warm up and stabilized for no load output before the start of the calibration. The no load output was noted (before taring) and the calibration signal was noted.

- Before the application of the calibration forces, the force transducer was preloaded thrice to its maximum capacity and kept at full load for 90 seconds.

- The calibration of the force transducer has been done in tension mode as well as compression mode.

- The calibration was carried out by applying two series of calibration forces in ascending order from $10 \%$ to $100 \%$ in steps of $10 \%$ at initial position, considered $0^{\circ}$.

- Two series of calibration forces have been applied at rotation positions $120^{\circ}$ and $240^{\circ}$.

- The force transducer was subjected to the full load once for about 90 seconds each time before starting the calibration to the new position.

- Between the loadings, readings corresponding to no load after waiting at least 30 seconds for the return to zero were noted.

The observed data has been tabulated and used to evaluate the relative error due to repeatability and reproducibility for the force transducers [7-9]. The relative errors, due to 
repeatability and reproducibility, have been plotted for the force transducers in manual mode and automatic mode and are summarized in form of plots (Fig.3-6). The relative errors for the $50 \mathrm{kN}$ force transducers have been plotted in range of $20 \mathrm{kN}-50 \mathrm{kN}$ only as up to as $20 \mathrm{kN}$, the force transducer of $20 \mathrm{kN}$ capacity has been considered. Relative error due to repeatability has been computed by taking into account the readings of force transducers at $0^{\circ}$, while the relative error due to reproducibility has been computed by taking the readings of force transducers at different positions, e.g., $0^{\circ}, 120^{\circ}$ and $240^{\circ}$, into account.

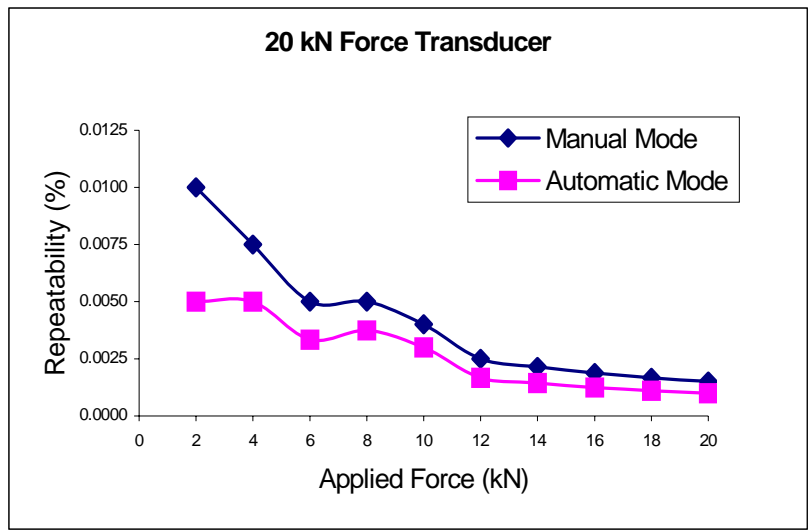

Fig.3. Repeatability Error for Manual \& Automatic Mode (20 kN Force Transducer)

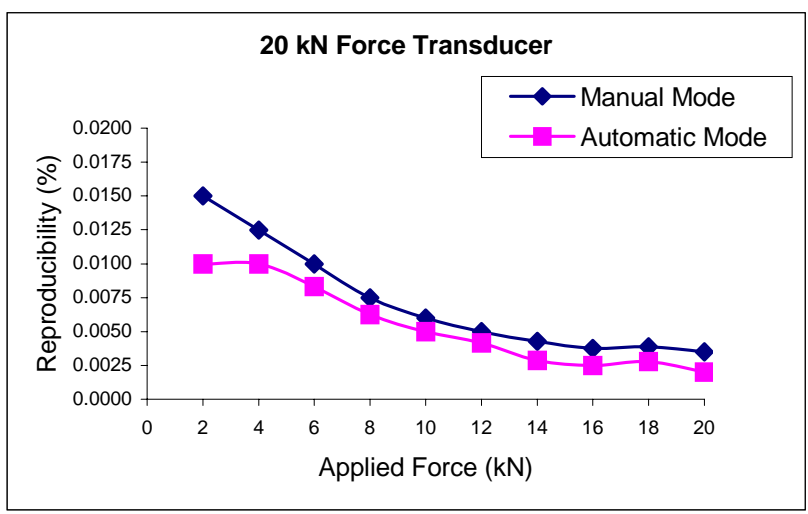

Fig.4. Reproducibility Error for Manual \& Automatic Mode (20 kN Force Transducer)

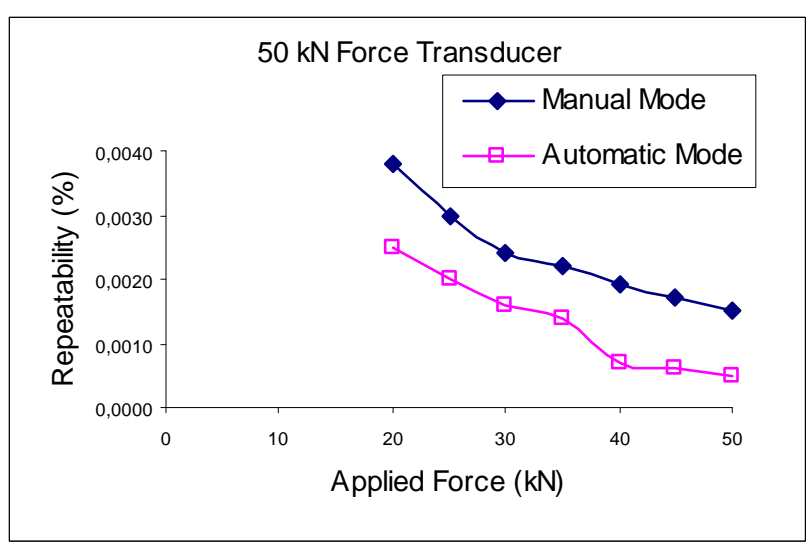

Fig.5. Repeatability Error for Manual \& Automatic Mode (50 kN Force Transducer)

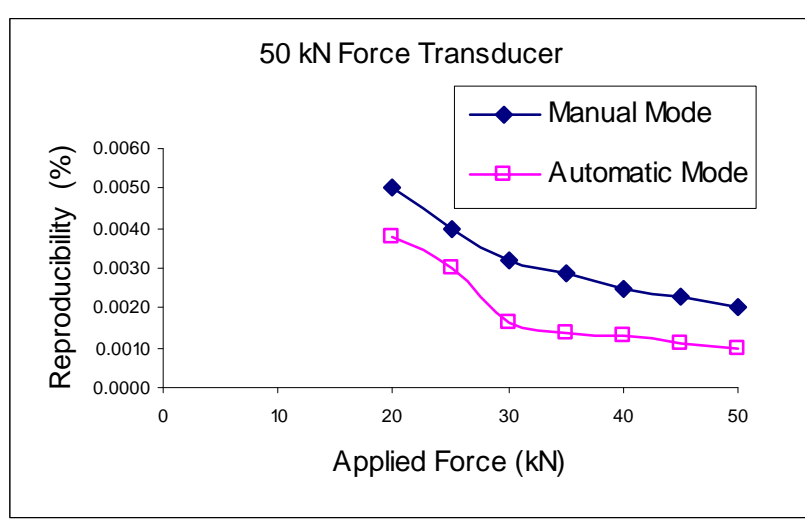

Fig.6. Reproducibility Error for Manual \& Automatic Mode (50 kN Force Transducer)

\section{RESULTS \& DISCUSSION}

The $50 \mathrm{kN}$ dead weight force machine has been automated and is used for metrological characterization of two precision force transducers of $20 \mathrm{kN}$ and $50 \mathrm{kN}$ capacity, respectively. The results show a distinct variation between the observations for manual mode and automatic mode calibrations of the force transducers. The results indicate about $0.0005 \%$ (5ppm) and $0.001 \%$ (10 ppm) variations in relative repeatability error and relative reproducibility error of force transducers, respectively, which may primarily be attributed due to the automation of the $50 \mathrm{kN}$ dead weight force machine. Though the differences in the deviations in manual and automatic mode may seem small, they are very significant as the uncertainty of the force transducers is \pm $0.004 \%$ and $\pm 0.005 \%$ (at $k=2$ ), respectively, and they have been found to have stable results over the years. The deviations obtained may be due to minimizing the factors due to human interference and factors other than the standard force machine itself. The factors may further include the errors due to operator while reporting the observations and sometimes may be due to the time interval in force application sequences. The uncertainties caused due to operator are usually dominant and must be evaluated for the given operator, but their evaluation is very difficult.

\section{CONCLUSIONS}

The two precision force transducers of $20 \mathrm{kN}$ and $50 \mathrm{kN}$ capacity considered for the study have been metrologically studied and their findings are summarized in the form of relative repeatability error and relative reproducibility error for manual and automatic modes of the automated $50 \mathrm{kN}$ dead weight force machine. The repeatability and reproducibility of the force transducers have been calculated and plotted for both modes. The results were obtained for both modes, the automatic mode indicates better metrological results for both force transducers. Hence, the present study discusses that the automation of the $50 \mathrm{kN}$ dead weight force machine and the automated calibration system were able to calibrate the force transducers. The metrological characterization of force transducers using 50 $\mathrm{kN}$ dead weight force machine has shown that the automation was able to improve the performance of the force machine by enabling measurements with complex 
sequences, precise control of loading time intervals, more consistent indicator readings and limited / no operator dependency.

\section{ACKNOWLEDGEMENTS}

The authors express their sincere thanks to Prof. R. C. Budhani, Director, National Physical Laboratory, New Delhi, India and Dr. A. K. Bandyopadhyay, Head, Apex Level Standards and Industrial Metrology Group, National Physical Laboratory, New Delhi, India.

\section{REFERENCES}

[1] Kruh, D., Benaim, N., Moscovitch, A. (1994). Computerized calibration system. Measurement, 13, 225-233.

[2] Yee, K.W. (1992). Automation of Strain Gauge Load cell Force Calibration. US Department of Commerce, Gaithersburg.

[3] GTM Gassmann Theiss Messtechnik GmbH (2010). GTM Force Manager User's Guide. Germany.
[4] Jain, K.K., Jain, S.K., Dhawan, J.K., Kumar, A. (2005). Realization of force scale upto $50 \mathrm{kN}$ through dead weight force machines at NPL, India. Mapan - J. Metrol. Soc. I., 20 (3), 249-257.

[5] Institute of Measurement and Control (1998). Guide to the Measurement of Force. London.

[6] International Standards Organization. (2004). Metallic Materials - Calibration of Force Proving Instruments used for the Verification of Uniaxial Testing Machines. ISO 376-2004.

[7] International Standards Organization (1995). ISO GUM Document - Guide for Estimation and Expression of Uncertainty of Measurement.

[8] European Association for Accreditation of Laboratories (1997). Expression of Uncertainty of Measurement in Calibration.

[9] National Accreditation Board for Testing and Calibration Laboratories (2000). NABL 141 Guidelines for Estimation and Expression of Uncertainty in Measurement. India.

Received February 1, 2011. Accepted May 30, 2011. 